DEPÓSITO LEGAL ZU2020000153

Esta publicación científica en formato digital

es continuidad de la revista impresa

ISSN 0041-8811

E-ISSN 2665-0428

Revista

de la

Universidad

del Tunlia

Fundada en 1947

por el Dr. Jesús Emrique Lossada

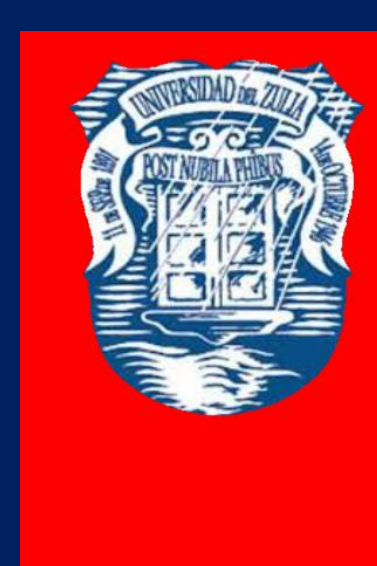

Ciencias

Sociales

y Arte

Aกัต 11 No 31

Septiembre - Diciembre 2021

Tercera ípoca

Maracailbo-Venezuela 


\section{Solidaridad y denuncia internacional de la CLAT-CMT sobre la situación de los derechos humanos y sindicales en Argentina (1976- 1982)}

Mario Ayala ***

RESUMEN

El objetivo de este artículo es reconstruir y analizar las acciones de solidaridad y denuncia internacional de la Central Latinoamericana de Trabajadores (CLAT), sede regional de la Confederación Mundial del Trabajo (CMT), con sede en Venezuela, sobre la situación de los derechos humanos y sindicales en Argentina bajo la última dictadura militar (1976-1983). La metodología de trabajo es cualitativa y su fuente principal fueron la prensa y documentos púbicos de la organización entre 1976 y 1982. Se concluye que este trabajo internacional de la CLAT-CMT hacia Argentina se planificó dentro de sus planes de acción en el Cono Sur bajo dictaduras de Seguridad Nacional, con el apoyo de sus organizaciones aliadas en Venezuela y la región; y se ejecutó mediante tres tipos de acciones que se articularon de diversa forma según la coyuntura y las prioridades: l) campañas internacionales de información y denuncia ante gobiernos extranjeros y la opinión pública mundial; 2) denuncia en organismos internacionales; 3) envío al país de misiones de observación, solidaridad y presión.

PALABRAS CLAVE: Central Latinoamericana de Trabajadores; dictadura argentina; solidaridad internacional; denuncia humanitaria; Venezuela.

* Docente. Instituto de Cultura, Sociedad y Estado, Universidad Nacional de Tierra del Fuego/CONICET), Argentina, mhayala@untdf.edu.ar

** Agradezco a la Dra. Gabriela Scodeller (CONICET-Universidad de Buenos Aires) por permitirme consultar la documentación sobre la CLAT que ella relevó en el International Institute of Social History de Ámsterdam en Holanda.

Recibido: 22/05/2020

Aceptado: 16/07/2020 


\section{Solidarity and international denunciation of the CLAT-CMT on the situation of human and trade union rights in Argentina (1976- 1982)}

ABSTRACT

The objective of this article is to reconstruct and analyze the solidarity actions and international denunciation of the Latin American Central of Workers (CLAT), regional headquarters of the World Confederation of Labor (WCL), based in Venezuela, on the situation of human rights and trade unions in Argentina under the last military dictatorship (1976-1983). The work methodology is qualitative and its main source was the press and public documents of the organization between 1976 and 1982. It is concluded that this international work of the CLAT-CMT towards Argentina was planned within its action plans in the Southern Cone under National Security dictatorships, with the support of their allied organizations in Venezuela and the region; It was carried out through three types of actions that were articulated in different ways according to the situation and priorities: 1) international information campaigns and denunciation before foreign governments and world public opinion; 2) complaint in international organizations; 3) sending the country on missions of observation, solidarity and pressure.

KEY WORDS: Latin American Central of Workers; Argentine dictatorship; international solidarity; humanitarian complaint; Venezuela.

Introducción

El 24 de marzo de 1976 tuvo lugar un golpe militar que derrocó al gobierno constitucional de Argentina encabezado por Isabel Martínez de Perón e instauró una dictadura de siete años hasta 1983. Los años previos al golpe pusieron en evidencia una profunda crisis de autoridad que paralizaba al tercer gobierno peronista (1973-1976). Fue una coyuntura de profunda crisis política y económica que se distinguió por la implementación de planes represivos que combinaron represión estatal y violencia paraestatal contra el proceso de radicalización política y los movimientos sociales y políticos movilizados, ya fueran estos contestatarios, rebeldes $y / o$ de intenciones revolucionarias (Franco, 2012: 15). Con el golpe de Estado y el nombramiento del general Jorge R. Videla como "presidente" de la Junta Militar estos métodos represivos se oficializaron y generalizaron (Suriano, 2003) en la forma de una política estatal planificada 
REVISTA DE LA UNIVERSIDAD DEL ZULIA. 3época. Año 11 N 31, 2020

Mario Ayala/// Solidaridad y denuncia internacional de la CLAT-CMT...271-301

DOI: http://dx.doi.org/10.46925//rdluz.31.18

y aplicada de forma clandestina. El modelo represivo de la dictadura militar se caracterizó por el uso masivo de los secuestros y detenciones ilegales, las torturas y las desapariciones forzadas de personas con el claro objetivo de aniquilar materialmente toda oposición como parte de un proyecto político global de reorganización de las relaciones sociales (Slatman \& Serra Padrós en Jensen \& Lastra, 2014: 257-258). Su política económica y laboral implicó el comienzo de un proceso de reconversión económica y social en el contexto de la crisis mundial desatada en 1973. A cargo del neoliberal Alfredo Martínez de Hoz, su objetivo global fue una transformación estructural de la economía y la sociedad argentinas (Canelo en Pucciarelli, 2004: 308), que se proponía acabar con el rol decisivo del Estado en la asignación de recursos y en la distribución del ingreso, que pasaría a estar supeditado al funcionamiento de los mercados (Suriano, 2003: 18).

La política dictatorial hacia el mundo del trabajo buscó el disciplinamiento laboral y la desarticulación del poder sindical, por la vía de la represión, la intervención de los sindicatos, los bajos salarios y la desocupación. Para someter a los obreros y silenciar a sus dirigentes gremiales y políticos los militares desplegaron acciones represivas que fueron desde la ocupación militar de lugares de trabajo hasta la persecución y desaparición física de militantes gremiales. La capacidad de resistencia de los trabajadores se redujo, pero con el tiempo reapareció recurriendo a repertorios de confrontación no tradicionales (Suriano, 2003: 19-20). Los militares también buscaron desestructurar el poder político y económico de los sindicatos tradicionales que se basaba en las condiciones de pleno empleo y en el poder político acumulado durante el tercer gobierno peronista que le permitió la sanción de la estratégica Ley de Asociaciones Profesionales. Esta norma fue aprobada a fines de 1973 y reconocía un solo sindicato por rama de actividad dotado de derecho a negociación con la patronal respectiva. La ley reforzaba el poder de la dirigencia sindical peronista tradicional que controlaba la Confederación General del Trabajo (CGT) en su enfrentamiento con sectores que respondían a la tendencia revolucionaria del peronismo y el sindicalismo combativo (Panella, 2017).

Desde inicios de la década del setenta la Central Latinoamericana de Trabajadores (CLAT), sede regional de la Confederación Mundial del Trabajo (CMT), tenía su sede regional en Caracas. Venezuela vivía desde 1958 bajo un régimen democrático 
REVISTA DE LA UNIVERSIDAD DEL ZULIA. 3época. Año 11 N 31, 2020

Mario Ayala/// Solidaridad y denuncia internacional de la CLAT-CMT...271-301

DOI: http://dx.doi.org/10.46925//rdluz.31.18

representativo bipartidista dominado por los partidos Acción Democrática (AD, socialdemócrata) y Comité de Organización Política Electoral Independiente (COPEI, socialcristiano). La estabilidad democrática venezolana y los vínculos con la dirigencia de COPEI y la Confederación de Trabajadores de Venezuela (CTV), brindaron a la CLAT ciertas libertades y garantías para realizar un trabajo político de denuncia de las dictaduras militares de la región hacia la esfera pública venezolana y el ámbito internacional. En el caso de Argentina durante la última dictadura este trabajo se definió por la denuncia las violaciones de los derechos humanos y sindicales y distintas acciones de solidaridad internacional con los sindicalistas y militantes gremiales que se encontraban en el interior o en el exilio (Ayala, 2017).

Dentro de Venezuela, la CLAT/CMT tenía organizaciones afiliadas que formaban una corriente importante dentro de la Confederación de Trabajadores de Venezuela (CTV), bajo la denominación de Confederación de Sindicatos Autónomos de Venezuela (CODESA), formando parte de sus órganos ejecutivos. La CLAT-CMT tenía una orientación socialcristiana inspirada en la doctrina del humanismo integral, no alineada, tercermundista, políticamente partidaria de una democracia integral y de un modelo socioeconómico autogestionario con participación de los trabajadores. En el contexto bipolar de la Guerra Fría, su proyecto sindical buscaba ocupar un espacio de representación en el sindicalismo regional, una suerte de "tercera posición" o "tercera vía" entre la proestadounidense Organización Regional Interamericana de Trabajadores (ORIT) de la Confederación Internacional de Organizaciones Sindicales Libres (CIOSL), y la procomunista Congreso Permanente de Unidad Sindical (CPUSTAL), dependiente de la Federación Sindical Mundial (FSM) (Godio y Wachendorfer, 2016: 7-8). Su proyecto estratégico era superar el sindicalismo tradicional y formar un Movimiento de los Trabajadores Latinoamericano como un vasto movimiento social que nucleara a los obreros, campesinos, pobladores, cooperativistas, profesionales y otros sectores que formaban el mundo del trabajo en América (CLAT, junio de 1978: 16-17). Su origen había sido la Confederación Latinoamericana de Sindicalistas Cristianos (CLASC) creada el 8 de diciembre de 1954 en Santiago de Chile, dependiente de la Confederación Internacional de Sindicatos Católicos (CISC), que a partir de 1968 paso a llamarse Central Mundial del 
REVISTA DE LA UNIVERSIDAD DEL ZULIA. 3época. Año 11 N 31, 2020

Mario Ayala/// Solidaridad y denuncia internacional de la CLAT-CMT...271-301

DOI: http://dx.doi.org/10.46925//rdluz.31.18

Trabajo, mientras que en 1971 la CLASC se transformó en la Central Latinoamericana de Trabajadores.

Los proyectos de formación sindical, creación de una red sindical afín y solidaridad transnacional de la CLASC/CLAT se llevaron adelante en el contexto internacional del conflicto bipolar de la Guerra Fría, y en el regional de radicalización política de las décadas de 1960 y 1970 (Scodeller, 2013). El principio de "solidaridad internacional de clase" con el que la CLAT/CMT enmarcó las acciones que analizaremos en este artículo remitía a la tradición del movimiento obrero de finales del siglo XIX. Sin embargo, el marco de la Guerra Fría dificultó la práctica internacionalista de muchas organizaciones políticas y sindicales subordinándolas a los intereses del conflicto bipolar, es decir a la defensa de los intereses "nacionales" y del "mundo libre" occidental o al seguidismo de los intereses diplomáticos de la URSS (Antentas \& Vivas, 2009: 33).

El contexto regional de radicalización de las décadas de 1960 y 1970 fue una época donde la percepción de que el mundo estaba al borde de cambiar era compartida por las izquierdas, derechas y los demócratas y fue contrarrestada por dictaduras apoyadas en la Doctrina de Seguridad Nacional anticomunista estadounidense. La valorización de la política y la expectativa revolucionaria de los sesenta latinoamericanos se desarrolló en contextos internos de fuertes luchas políticas y sociales, crisis de los proyectos desarrollistas de posguerra, dictaduras militares y un escenario mundial signado por el triunfo de la Revolución Cubana, la descolonización africana, la guerra de Vietnam, la rebelión antirracista en los Estados Unidos y los diversos brotes de rebeldía juvenil en el tercer mundo (Pettiná, 2018: Gilman, 2003). Vistos desde los despachos de la alta política estadounidense y europea, estos procesos diversos que cuestionaban el statu quo geopolítico de la Guerra Fría, debían ser revertidos o contenidos en sus niveles políticos, ideológicos, organizativos y socioeconómicos. Como demuestran los estudios de la nueva historia de la Guerra Fría global, en los sesenta y setentas el proceso de distención entre ambas potencias se limitó a Europa y tuvo una escalada en el tercer mundo y América Latina (Pettina, 2018). De modo que durante la década del setenta no existió una distención en las relaciones interamericanas, sino que la guerra fría continuó en el sur de forma feroz, radical y violenta. A partir del golpe de militar de Chile en 1973 se inició la instauración de un nuevo orden 
REVISTA DE LA UNIVERSIDAD DEL ZULIA. 3época. Año 11 N 31, 2020

Mario Ayala/// Solidaridad y denuncia internacional de la CLAT-CMT...271-301

DOI: http://dx.doi.org/10.46925//rdluz.31.18

contrarrevolucionario en el Cono Sur (Harmer, 2013:12). El cuadro regional y temporal de nuestro análisis se completa con el inicio de actividades en la región de organizaciones políticas internacionales socialcristianas y socialdemócratas con base en Europa occidental buscando establecer relaciones con partidos, sindicatos y académicos, entre los cuales destacaron la Fundación Konrad Adenauer (KAS), la Fundación Friedrich Ebert (FES) y la Internacional Socialista (IS).

La CLAT-CMT aún no cuenta con una investigación que analice su historia como organización de un modo sistemático. Ha sido abordada en el marco de análisis generales sobre el sindicalismo cristiano latinoamericano (Parker, 1988; Wahlers, 1991), de las centrales sindicales internacionales durante la Guerra Fría (Godio y Wachendorfer, 1986), de los proyectos de la Fundación Konrad Adenauer en América Latina (Thesing, 2011) y en estudios sobre las relaciones del sindicalismo argentino con el latinoamericano (Parcero, 1987; Parcero y Morant, 2016). Más recientemente Gabriela Scodeller (2011; 2015; 2016) estudió en profundidad su política de formación sindical, las ideas fuerza de su proyecto y sus conexiones con agrupaciones sindicales de argentina durante las décadas de 1960 y 1970. Mientras que Mónica Gordillo (2017; 2020) se encuentra investigando el rol de la CLAT dentro de las redes sindicales transnacionales de solidaridad sindical durante el último ciclo las dictaduras en el Cono Sur de América Latina.

El objetivo de este artículo es reconstruir y analizar las acciones de solidaridad y denuncia internacional de la CLAT/CMT sobre la situación de los derechos humanos y sindicales en Argentina bajo la última dictadura militar (1976-1983). Sus fuentes principales fueron las revistas Cuadernos de la CLAT (trimestral, editada entre 1976-1978), Informativo de la CLAT. Vocero del movimiento de los trabajadores comprometidos con la liberación de los pueblos de América Latina (mensual, editada a partir de 1976) y la documentación de los Congresos de la central editada en el período 1976-1982. La mayoría de la misma es conservada en el International Institute of Social History de Ámsterdam en Holanda. La reconstrucción mostró la dimensión transnacional de los planes de acción de la CLAT/CMT en el marco global de la Guerra Fría y en sus escalas regionales y nacionales, a partir del rol de la CODESA y la CTV en acciones que se activaron desde Venezuela hacia la región y el mundo, así a como las agrupaciones sindicales afiliadas a la CLAT dentro de Argentina nucleadas en el Consejo 
REVISTA DE LA UNIVERSIDAD DEL ZULIA. 3época. Año 11 N 31, 2020

Mario Ayala/// Solidaridad y denuncia internacional de la CLAT-CMT...271-301

DOI: http://dx.doi.org/10.46925//rdluz.31.18

Coordinador Sindical Argentino (CCAS). Se concluye que el trabajo solidaridad y denuncia internacional de la CLAT-CMT hacia las violaciones de los derechos humanos y sindicales en Argentina se planificó dentro de sus planes de acción en el Cono Sur bajo dictaduras de Seguridad Nacional, con el apoyo sus organizaciones aliadas en Venezuela y la región; y se ejecutó mediante tres tipos de acciones que se articularon de diversa forma según la coyuntura y las prioridades: 1) campañas internacionales de información y denuncia ante gobiernos extranjeros y la opinión pública mundial; 2) denuncia en organismos internacionales; 3 ) envío al país de misiones de observación, solidaridad y presión.

1. El plan de acción de denuncia y solidaridad internacional de CLAT-CMT ante las dictaduras de América Latina

A fines de octubre de 1976 el Comité Confederal de la CMT se reunió por primera vez en América Latina, en la sede de la CLAT-Universidad de los Trabajadores de América Latina (UTAL) de Caracas. En su documento final, "Declaración contra el fascismo de la CTM sobre América Latina", denunció "la escalada totalitaria fascista que tiende a generalizarse en el continente" y, junto a la CLAT, se comprometió "en un esfuerzo de solidaridad para con los militantes y las organizaciones víctimas de la represión" y "tomo medidas con miras a desarrollar mejor esa solidaridad efectiva, particularmente movilizar organizaciones sindicales y la opinión publica en una campaña vigorosa contra la escalada fascista" (CLAT, noviembre de 1976: 8-9). La elección de Venezuela para la reunión marcó la importancia que daba la central mundial socialcristiana a la situación de los trabajadores de la región ${ }^{1}$, poniendo el acento en la emergente crisis regional de violaciones de derechos humanos y sindicales con origen en el Cono Sur después del golpe militar en Argentina, entre otros temas (CLAT, diciembre de 1976: 5). El resultado de la reunión Comité Confederal de la CMT fue la definición de un plan de acción local, regional e internacional

\footnotetext{
${ }^{1}$ Y tal vez también subrayando que la competencia entre centrales sindicales internacionales por obtener presencia en América Latina tuvo como puerta de ingreso y asentamiento a Venezuela con su sistema democrático estabilizado y dirigido por los partidos socialdemócratas y socialcristianos - desde el cual se podrían articular políticas hacia la región. Los líderes sindicales que integraban el Comité Confederal eran Marcel Pepin (Presidente, Canadá), Emilio Máspero (Vicepresidencia, América Latina) y Jean Kulakoski (Secretario General, Bélgica).
} 
REVISTA DE LA UNIVERSIDAD DEL ZULIA. 3e época. Año 11 N³1, 2020

Mario Ayala/// Solidaridad y denuncia internacional de la CLAT-CMT...271-301

DOI: http://dx.doi.org/10.46925//rdluz.31.18

para contrarrestar las violaciones de los derechos humanos y sindicales en América Latina a partir de un trabajo en tres ámbitos: 1) acción urgente y más precisa en las Naciones Unidas; 2) acción sindical sobre los gobiernos de los países de la Comunidad Europea, Canadá y los Estados Unidos; y 3) movilizar, mediante campañas de información y denuncia a los sindicatos de los países industrializados de Europa Occidental, Canadá y Estados Unidos para lograr solidaridad política y material y formar un movimiento sindical solidario.

A partir de este plan de acción de 1976, y por varios años, las tareas de solidaridad y denuncia de violaciones a los derechos humanos y sindicales se transformaron en un eje de acción prioritario de la CLAT/CMT como parte de su trabajo de coordinación sindical regional y activismo transnacional. El análisis de su prensa y documentos públicos muestra que para cumplir con estos objetivos entre 1976 y 1982 la CLAT-CMT llevo adelante acciones tales como: 1) presentación de información probatoria de violaciones de derechos humanos y sindicales ante gobiernos, organismos internacionales y medios de comunicación; 2) movilizaciones de protesta ante embajadas, consulados y/o delegaciones oficiales de los países que violaban los derechos humanos; 3) acciones de boicot de las relaciones exteriores políticas, económicas y militares; 4) misiones de observación, información y presión a los países bajo dictaduras y de solidaridad con las organizaciones sindicales; 5) campañas internacionales de denuncia y solidaridad que buscaban contribuir a la formación de una corriente de opinión mundial informada y critica y de un movimiento sindical solidario; y 6) el apoyo a presos, desaparecidos, perseguidos y exiliados del mundo sindical.

El fuerte de la acción sindical de la CLAT-CMT estuvo en Venezuela y República Dominicana (re-democratizada en 1978) y en países de Europa occidental como Bélgica, Holanda y Alemania. Razón por la cual la central sindical denunció ante la opinión pública y los gobiernos estas naciones y solicitó la solidaridad de las organizaciones sindicales, políticas y religiosas, con el objetivo de ejercer presión internacional sobre los gobiernos y dictaduras militares que violaban los derechos humanos y sindicales. Estas iniciativas incrementaron su presencia en América del Sur, exigiendo a los gobiernos dictatoriales de Argentina, Bolivia, Brasil, Chile, Paraguay, Perú y Uruguay garantizar los derechos humanos y sindicales. 
REVISTA DE LA UNIVERSIDAD DEL ZULIA. $3^{a}$ época. Año 11 N 31, 2020

Mario Ayala/// Solidaridad y denuncia internacional de la CLAT-CMT...271-301

DOI: http://dx.doi.org/10.46925//rdluz.31.18

Durante el período temporal que abarca este este estudio la CLAT-CTM también insistió en el carácter "fascista" de las dictaduras del Cono Sur y condenó con fuerza los "totalitarismos de izquierda y derecha" porque ambos "aplastaban la libertad de los trabajadores". Y del mismo modo denunciaron el rol funcional del "sindicalismo libre" que respondía "a la ORIT y, por ende, a la estrategia del imperialismo norteamericano y las empresas transnacionales" que apoyaban, por ejemplo, a los gobiernos autoritarios de Chile, Brasil, Paraguay o México. También criticaron el apoyo y/o silencio cómplice de la CPUSTAL-FSM y los partidos comunistas hacia algunos gobiernos militares como los de Argentina, Ecuador o Perú (véase CLAT, 1978; CLAT, octubre de 1980: 5). Además, a lo largo de toda la década del setenta y ochenta la CLAT expresó su rechazo del fenómeno guerrillero y de la lucha armada (CLAT, marzo de 1980: 2) en la región, defendiendo métodos no violentos, de masas y de concientización política². El financiamiento de las actividades de la CLASC/CLAT provino principalmente del Instituto de Solidaridad Internacional (ISI) de la fundación alemana Konrad Adenauer (KAS) ${ }^{3}$. Si bien la central hizo hincapié en el autofinanciamiento de la organización, ello era algo difícil de lograr dada la escasa capacidad financiera de los adherentes de la región (Scodeller, 2015:8). Según un funcionario de la KAS para América Latina de aquella época, entre 1962 y 1974 la capacitación sindical tuvo máxima prioridad en el catálogo de proyectos de la Fundación y "contó con un presupuesto total de 33.800.000 millones de marcos" (Thesing, 2011:182).

Dentro de sus planes de acción hacia países sudamericanos bajo dictaduras de Seguridad Nacional, la CLAT y la CMT llevaron a cabo campañas de denuncia y solidaridad que enmarcaron en la tradición de la "solidaridad internacional de clase" del movimiento obrero y la defensa de los derechos humanos. El accionar de la organización en el caso de Argentina bajo la última dictadura militar, entre 1976 y 1982 identificamos tres tipos de acciones que se articularon de diversa forma según la coyuntura y prioridades de la

2 Véase por ejemplo las declaraciones del Secretario General de la CLAT, Emilio Máspero, en relación a la toma del Palacio Nacional de Nicaragua por el Frente Sandinista de Liberación Nacional (CLAT, septiembre de 1978).

${ }^{3}$ La KAS fue creada en 1955 por el partido Unión Demócrata Cristiana de Alemania para fomentar a nivel mundial los ideales demócrata cristianos y socialcristianos. En 1962 inició sus actividades en América Latina en coordinación con los partidos democratacristianos de Chile (Partido de la Democracia Cristiana) y Venezuela (COPEI) y con la Confederación Latinoamericana de Sindicalistas Cristianos (Thesing, 2011). 
REVISTA DE LA UNIVERSIDAD DEL ZULIA. 3época. Año 11 N 31, 2020

Mario Ayala/// Solidaridad y denuncia internacional de la CLAT-CMT...271-301

DOI: http://dx.doi.org/10.46925//rdluz.31.18

organización: 1) campañas internacionales de información y denuncia ante gobiernos extranjeros y la opinión pública mundial; 2) denuncia en organismos internacionales; 3) envío de misiones de observación, solidaridad y presión al país. Dedicamos los siguientes apartados a reconstruir cada una de estas líneas de acción.

2. Campañas internacionales de denuncia e información sobre la situación argentina desde Venezuela y Europa

Las campañas internacionales de denuncia e información de la CLAT-CMT sobre la situación argentina articularon distintas acciones e iniciativas realizadas desde Venezuela y Europa cuyos actores meta estaban en el ámbito internacional. Un examen atento de los materiales producidos por la organización sindical regional muestra que las campañas incluyeron (o a veces se complementaron con) gestiones ante organismos internacionales y misiones de observación, presión y solidaridad; y que fueron diferenciadas por la organización entre "campañas" y “campañas rápidas", de acuerdo a su grado de planificación, duración y urgencia.

Pero icómo se materializaron estas iniciativas? Por ejemplo, en la segunda mitad de 1976 durante una visita a Europa del Ministro de Hacienda de la dictadura militar, Martínez de Hoz, la CLAT-CMT realizó en varios países europeos "una campaña de información, denuncia y presión ante autoridades, opinión pública y organizaciones sindicales para obtener la liberación de los sindicalistas presos en Argentina, mayor respeto de los derechos humanos y pronto retorno a la democracia" (CLAT, diciembre de 1976: 4).

Durante 1977 la organización activó campañas mundiales y regionales por casos de presos y desaparecidos. El año comenzó con una campaña mundial urgente por la aparición con vida de Jorge Di Pascuale, Secretario General de la Federación de Trabajadores de Industrias Farmacéuticas, secuestrado y desaparecido en Buenos Aires el 31 de diciembre de 1976 (CLAT, febrero de 1977: 11).

En mayo las organizaciones vinculadas a la CLAT en Venezuela realizaron actividades de información, protesta y denuncia de la situación argentina en el marco de la visita oficial del Jefe de la Junta Militar, general Videla, la primera que realizaba este dictador a un país democrático. En esa coyuntura la CLAT realizó innumerables acciones y 
REVISTA DE LA UNIVERSIDAD DEL ZULIA. $3^{a}$ época. Año 11 N 31, 2020

Mario Ayala/// Solidaridad y denuncia internacional de la CLAT-CMT...271-301

DOI: http://dx.doi.org/10.46925//rdluz.31.18

gestiones dentro y fuera de Venezuela. La primera de ellas fue informar en detalle la grave situación humanitaria y económica de Argentina a un año del golpe de Estado. El Informativo CLAT denunció la existencia de "30 mil presos políticos, miles de asesinados, miles de desaparecidos", como parte del cuadro de terror instalado por la dictadura militar. Se destacaba la prohibición dictatorial de las actividades políticas y sindicales; que el país atravesaba la peor crisis económica de la historia del país, y la baja del salario real desde el golpe. Y finalizaba con los reclamos de la CLAT al régimen militar argentino:

... respeto de las garantías individuales y derechos humanos, la libertad de dirigentes y activistas del movimiento de los trabajadores detenidos, la libertad para la acción sindical, y la restitución de los organismos gremiales a los trabajadores, así como la necesidad de un pronto retorno a la normalidad constitucional. (CLAT, abril de 1977: 16)

La segunda acción organizada en el marco de la visita de Videla a Caracas fue una "campaña rápida" de alcance mundial por la libertad del gremialista correntino Alfredo Carazo. En una nota que reseñaba esta acción, la CLAT denunciaba a la dictadura argentina por "su detención e intención de involucrarlo en actividades subversivas" (CLAT, mayo de 1977: 1) como parte de la campaña de persecución de dirigentes obreros. Asimismo, se informaba que la CMT había solicitado "una rápida intervención de organismos internacionales y gobiernos europeos a favor del detenido", y también que hubo gestiones en el mismo sentido en Venezuela mediante

....legisladores y dirigentes de la CTV, que han intercedido ante el gobierno del país hermano [Argentina], a fin de que revise la situación del detenido, adoptando en caso contrario la actitud de solicitar al gobierno de Venezuela, que revea el próximo viaje del Presidente Argentino a ese país. Por último, la CLAT y sus organizaciones afiliadas continúan su acción para asegurar, a través de una rápida movilización, la vida, la libertad y seguridad de este dirigente, haciendo valer el principio de solidaridad internacional de los trabajadores, en defensa de vigencia de la libertad sindical y la vigencia de los derechos humanos. (CLAT, mayo de 1977: 1)

La campaña por la libertad de Carazo - que fue liberado y salió al exilio venezolano ${ }^{4}$ fue secundada por importantes acciones de sus organizaciones afiliadas nucleadas en la

\footnotetext{
${ }^{4}$ Carazo fue liberado, pues en noviembre de 1977 participó del VII Congreso de la CLAT en Costa Rica (véase CLAT, noviembre de 1977: 13).
} 
REVISTA DE LA UNIVERSIDAD DEL ZULIA. $3^{a}$ época. Año 11 N 31, 2020

Mario Ayala/// Solidaridad y denuncia internacional de la CLAT-CMT...271-301

DOI: http://dx.doi.org/10.46925//rdluz.31.18

CODESA. Por ejemplo, la dirigencia de la CTV y parlamentarios de origen sindical denunciaron a la dictadura ante la opinión pública nacional y manifestaron su desacuerdo con la visita de Videla y exigieron al presidente Carlos Andrés Pérez (1974-1979) condenar la violación de derechos humanos y de los trabajadores en Argentina y exigir el retorno a la democracia. Por su parte, los miembros del Comité Ejecutivo de la CTV solicitaron y obtuvieron una entrevista con Videla en la que le exigieron la libertad de los presos sindicales, la aclaración sobre los secuestros de sindicalistas, la devolución de los sindicatos y el respeto de los derechos humanos, entre otras (CLAT, junio de 1977: 8).

Cinco meses después, la CLAT impulsó en el XIX Congreso Mundial de la CMT (Bélgica, 17-21 octubre 1977) una declaración dirigida por telegrama al gobierno dictatorial argentino-suscripta por Jean Kulakowsky y Marcel Pepin, Secretario general y presidente de la CMT, respectivamente- para "reiterar la solidaridad de clase ante los trabajadores y[su] pueblo", reclamar por las trabas a la salida del país de la delegación gremial que participaría del $X I X$ Congreso, y exigiendo "libertades de dirigentes y militantes sindicales, esclarecimiento desaparecidos [sic], garantías personales sindicalistas, normalización actividades sindicales respetando convenciones OIT, devolución de la CGT a sindicatos legítimos representantes trabajadores"(CLAT, noviembre de 1977: 6).

Durante los años siguientes la CLAT continuó con sus campañas internacionales y acciones urgentes en defensa de los derechos sindicales y humanos en Argentina y otros países de la región bajo dictaduras. En marzo de 1978 organizó una campaña exigiendo a la dictadura argentina la liberación de Amílcar González, Secretario del Sindicato de Prensa de Mar del Plata y miembro del Comité Ejecutivo de la Federación Latinoamericana de Trabajadores de Prensa (FELATRAP), encarcelado desde el golpe de Estado (CLAT, marzo de 1978: 7). ${ }^{5}$ Y en mayo emprendió una campaña rápida para denunciar la desaparición

\footnotetext{
${ }^{5}$ La FELATRAP y la CMT-CLAT realizaron una intensa campaña internacional por la libertad de Amílcar González que incluyo diversos actores internacionales, como Amnistía Internacional de Holanda, entre otras. La dictadura expulsó a González concediéndole el Derecho de Opción en abril de 1978, trasladándose a Roma con el apoyo de la CLAT-CMT. La central declaró al respecto: "La libertad de Amílcar González, es otro triunfo de la solidad de clase, concreta, constante y efectiva que desarrollaron la CLAT y la FELATRAP y debe servir para impulsar con mayor vigor la denuncia sobre la grave situación que padecen los trabajadores de prensa de América Latina..." (CLAT, junio de 1978: 13).
} 
REVISTA DE LA UNIVERSIDAD DEL ZULIA. $3^{a}$ época. Año 11 N 31, 2020

Mario Ayala/// Solidaridad y denuncia internacional de la CLAT-CMT...271-301

DOI: http://dx.doi.org/10.46925//rdluz.31.18

Roberto Repetto, Secretario General de Unión Personal Civil del Estado (UPCN), inscribiendo el hecho represivo en "una larga campaña contra el movimiento obrero organizado argentino que realiza el actual régimen militar" (CLAT, junio de 1978: 24). ${ }^{6}$

El año 1979 fue de los más activos en las campañas y acciones de denuncia y solidaridad de la CLAT-CMT en relación a la situación de Argentina. Comenzó en los meses de febrero y marzo con una campaña mundial de CLAT-CMT por los presos y desaparecidos. En Europa las organizaciones sindicales afiliadas a la CMT realizaron denuncias ante la opinión pública local e internacional y efectuaron entrevistas con funcionarios de embajadas argentinas (CLAT, abril de 1979: 22). Mientras en Venezuela la CLAT y el Consejo Coordinador Sindical de Argentina (CCSA), red sindical afín, solicitaron al presidente socialcristiano Luis Herrera Campins (1979-1984) que interveniera ante el gobierno militar argentino por la libertad de presos sindicales y por el esclarecimiento de las desapariciones, presentándole ejemplos de casos concretos, y subrayando que el pedido formaba "parte de una intensa campaña de la CLAT para lograr la libertad de todos los presos sindicales, el esclarecimiento del destino de los desaparecidos y la normalización del movimiento obrero argentino" (CLAT, marzo de 1979: 3).

Al mismo tiempo, un examen de las acciones de la CLAT a lo largo de 1979 también muestra que ese año inició una apertura y ampliación de su línea de denuncia y solidaridad en relación a la Argentina, que hasta ese momento había estado concentrada exclusivamente en el ámbito sindical y laboral. En consecuencia, a partir de 1979 la CLAT comenzó a reconocer e interactuar con otros actores de la denuncia humanitaria y la solidaridad que realizaban su trabajo en Venezuela y en el interior de Argentina, principalmente con las organizaciones pro-derechos humanos vinculadas a redes cristianas y ecuménicas. Un primer ejemplo que sugiere esta mudanza de línea fue su participación con una ponencia sobre su trabajo de solidaridad internacional en las "Jornadas de Solidaridad Latinoamericana" (Caracas el 9 de marzo de 1979), organizadas por el Programa Venezolano

\footnotetext{
${ }^{6}$ Según la nota "La CLAT y sindicatos adheridos se dirigieron a las autoridades militares para exigir la aparición del sindicalista y también informaron del caso a la OIT, ONU, AI y la Comisión Justicia y Paz del Vaticano "a fin de denunciar esta grave violación, y su inmediata intervención para demandar ante ese gobierno la explicación sobre este suceso y que se garantice a libertad del compañero Roberto Repetto" (CLAT, junio de 1978: 24). Repetto había sido secuestrado el 22 de marzo de 1978.
} 
REVISTA DE LA UNIVERSIDAD DEL ZULIA. 3época. Año 11 N 31, 2020

Mario Ayala/// Solidaridad y denuncia internacional de la CLAT-CMT...271-301

DOI: http://dx.doi.org/10.46925//rdluz.31.18

Pro-Refugiado Latinoamericano (ProRefugiado) y la Fundación Latinoamericana para el Desarrollo Social (FundaLatin) en apoyo y solidaridad con los comités de exiliados latinoamericanos con sede en Caracas, de las que participaron representantes de los diferentes comités, denunciando la graves situaciones represivas que se vivían en Argentina, Haití, El Salvador, Nicaragua, Chile, Uruguay y Paraguay (CLAT, abril de 1979; Ayala, 2017). Esta fue la primera vez que la CLAT participó de un evento que reunía en Venezuela a comités de exiliados latinoamericanos y también era la primera oportunidad desde inicios de 1976 en que hizo referencias a los comités de exiliados locales en su prensa. Hasta ese momento habían mantenido una tajante distancia con los exiliados argentinos, pues estaban asociados a las organizaciones de la izquierda armada y no armada (véase Afattato, 2013).

Otro ejemplo de esta apertura de su línea de solidaridad sucedió en el mes de julio de 1979 cuando la CLAT denunció públicamente la represión contra organizaciones de derechos humanos dentro de la Argentina en los meses previos a la visita de la Comisión Interamericana de Derechos Humanos de la Organización de los Estados Americanos (CIDH-OEA) a este país ${ }^{7}$. La central envió un telegrama a la junta militar argentina "protestando por el allanamiento de los locales de la Asamblea Permanente de los Derechos Humanos, la Comisión de Familiares de Desaparecidos y la Liga de los Derechos del Hombre, exigiendo pleno respeto de los derechos humanos", subrayando que "estas acciones represivas se producen ante la inminente visita de la CIDH de la OEA que debe arribar al país el próximo 6 de septiembre", y señalando que el "principal motivo de esta comisión, será la investigación de los millares de denuncias sobre "desaparecidos", secuestrados, asesinados, los presos políticos y la represión que pesa sobre la sociedad argentina" (CLAT, agosto de 1979: 8).

Finalmente, esta apertura de la línea también pueden reconocerse en el Plan de Acción de 13 puntos aprobado para 1980 por el XVII Consejo Latinoamericano de la CLAT (3-7 diciembre de 1979), en el cual se incorporaban reivindicaciones de actores no sindicales que luchaban contra las dictaduras en el ámbito interno y externo, como las organizaciones de solidaridad y de exiliados centradas en la defensa de los derechos humanos y la exigencia del retorno de la democracia, el fin de la represión, las amnistías y el derecho al retorno:

${ }^{7}$ Un análisis detallado de la visita de CIDH puede consultarse Jensen (2010). 
REVISTA DE LA UNIVERSIDAD DEL ZULIA. $3^{a}$ época. Año $11 N^{\circ}$ 31, 2020

Mario Ayala/// Solidaridad y denuncia internacional de la CLAT-CMT...271-301

DOI: http://dx.doi.org/10.46925//rdluz.31.18

[La CLAT, en] respuesta al actual drama latinoamericano y propone luchar por las siguientes reivindicaciones inmediatas: 1 . Por las libertades democráticas y los derechos sindicales de los trabajadores y sus organizaciones [...] 5. Por el cese de la represión, la repatriación de los exiliados, la amnistía de los presos políticos y sindicales, la reposición de todos los trabajadores despedidos, la eliminación los juicios sumarios, el cese del sistema de desapariciones y asesinatos. /6. Por la libertad y los derechos democráticos del pueblo, la instauración de gobiernos civiles y democráticos con la participación activa de los trabajadores organizados en los procesos y decisiones políticas. (CLAT, febrero de 1980: 23-24)

En este marco de definiciones de sus acciones transnacionales, durante junio y julio de 1981 la CLAT organizó una campaña internacional para garantizar la vida, la libertad y los derechos de funcionamiento del Servicio Paz y Justicia (SERPAJ) de Argentina y de su director el Premio Nobel de la Paz Adolfo Pérez Esquivel. En la Argentina los miembros de esta organización de derechos humanos de origen cristiano estaban siendo víctimas de acciones represivas y de intimidación con atentados contra su local, amenazas de muerte y detenciones (CLAT, julio de 1981: 9).

La última campaña internacional de la CLAT en relación a la Argentina de que la tenemos registro no fue para denunciar violaciones de derechos humanos, sino la organización de un "paro general latinoamericano" para el 10 de junio de 1982, en solidaridad con la posición argentina en la guerra de las islas Malvinas (abril-junio de 1982). La acción pretendía solidarizarse "con el pueblo y los trabajadores de Argentina", expresar su rechazo a "la agresión colonialista e imperialista angloamericana", "defender la soberanía nacional latinoamericana y avanzar hacia la democracia y la justicia social". Como parte de esta campaña la CLAT-CMT apoyó a la delegación de la CGT argentina en la OIT, solicitó a sus dirigentes que "dispusieran las medidas pertinentes para que todos los trabajadores argentinos se incorporen a este paro", y envío misiones de sus militantes a la Argentina y otros países de la región "para impulsar y concretar esta iniciativa de solidaridad continental y apurar los pasos para la democratización efectiva de todas las Naciones de la región" (CLAT, junio de 1982: 2). Algunos detalles de la actividad de esta la misión CLAT de sindicalistas venezolanos que visitó la Argentina para la preparación del paro latinoamericano se conocen a partir de los informes Dirección de Inteligencia de la Policía de la Provincia de Buenos Aires (DIPBA) que los vigiló y siguió durante su estadía en 
REVISTA DE LA UNIVERSIDAD DEL ZULIA. $3^{a}$ época. Año $11 N^{\circ}$ 31, 2020

Mario Ayala/// Solidaridad y denuncia internacional de la CLAT-CMT...271-301

DOI: http://dx.doi.org/10.46925//rdluz.31.18

Buenos Aires, lo que hace suponer con seguridad que las anteriores misiones también fueron sometidas a las mismas tareas de inteligencia e intimidación (DIPBA, 1982). La campaña tuvo alguna repercusión en Venezuela y países de la región donde la CLAT tenía presencia sindical. Sin embargo, no encontramos referencias concretas de su alcance y resultados, salvo la aclaración realizada por sus dirigentes de que la protesta fue organizada destacando que "no se podía lograr soberanía nacional sin un real ejercicio de la soberanía política" 8

Este último ejemplo muestra claramente el modo en que las campañas de la CLAT/CMT incluyeron un trabajo conjunto de gestiones ante organismos internacionales y misiones de observación, presión y solidaridad.

\section{Denuncias en organismos internacionales}

Durante la última dictadura argentina la CLAT-CMT también denunció a la política laboral y represiva del Estado argentino ante los organismos internacionales intergubernamentales como la OEA, la ONU, la OIT y en los no gubernamentales como Amnistía Internacional, el Tribunal Russel II, Vaticano y el Servicio Paz y Justicia, entre otros. Pero debido a su carácter de organización sindical internacional el organismo más utilizado fue la OIT, ámbito en el que tenían una comprobada experiencia. Desde la década del sesenta CLASC/CLAT y la CMT habían aprovechado las conferencias y reuniones de la OIT para denunciar a las dictaduras de la región ${ }^{9}$, apoyando y dando voz a los sindicalistas proscriptos, perseguidos y/o exiliados a través de las delegaciones latinoamericanas y mundiales afines, diferenciándose de la denuncia "selectiva", y en muchos casos la actitud cómplice, de la CIOLS y la FSM, exigiendo condenas, sanciones y visitas de comisiones de investigación y observación (CLAT, noviembre-diciembre de 1979). En el caso específico de Argentina durante la última dictadura militar sus denuncias ante la OIT fueron permanentes y se enfocaron en las violaciones a los derechos humanos, sindicales y laborales exigiendo condenas, sanciones y controles por una Comisión de la OIT que visitara el país

\footnotetext{
${ }^{8}$ Véase entrevista a Emilio Máspero (Secretario General de la CLAT) en Parcero, 1987.

${ }^{9}$ Por ejemplo, en la Conferencia de OIT de noviembre de 1974 en México la CLAT reclamó "una amnistía general para todos los trabajadores del campo y la ciudad que se ven privados de sus derechos y libertades en los campos de concentración y en las cárceles de la mayoría de los países de nuestro continente" y llamó a la solidaridad sindical mundial (CLAT, septiembre-noviembre de 1976: 9).
} 
REVISTA DE LA UNIVERSIDAD DEL ZULIA. 3e época. Año 11 N³1, 2020

Mario Ayala/// Solidaridad y denuncia internacional de la CLAT-CMT...271-301

DOI: http://dx.doi.org/10.46925//rdluz.31.18

para investigar la política laboral, económica y represiva. Al mismo tiempo utilizó -y brindó- su espacio de representación en OIT para realizar reclamos en favor de grupos de casos específicos de sindicalistas y trabajadores proscriptos, presos o desaparecidos de Argentina y demás países latinoamericanos.

Entre septiembre y octubre de 1976 la CMT presentó una denuncia formal ante la OIT por "serias violaciones de los derechos humanos y sindicales en Argentina", cuyos reclamos se repetirían en varias ocasiones durante los siete años siguientes: las detenciones sin causa ni proceso de dirigentes sindicales y trabajadores, los casos de desaparición forzada, la intervención de los sindicatos, el no respeto de los derechos laborales, humanos y sindicales y de las conquistas adquiridas y su reemplazo por una legislación represiva, que implicaba graves violaciones a los Convenios de la OIT (véase CLAT, diciembre de 1976: 14).

Durante 1977 la CLAT mantuvo su acción de denuncia internacional concentrada en la OIT y la OEA. En junio presentó un informe sobre la situación de los trabajadores de la región ante la VII Reunión de la Asamblea General de la OEA que sesionó en Granada, reclamando una amnistía general de presos políticos y sindicales (CLAT, diciembre de 1977:1). Mientras que en la OIT informó sobre la negativa de organizaciones sindicales argentinas a integrar la delegación oficial que debía concurrir a la $63^{\circ}$ Conferencia del organismo en protesta por las políticas laborales y económicas del gobierno militar y reclamó por la libertad de los presos sindicales y trabajadores de grupos cristianos de base, la normalización sindical, y particularmente contra el proyecto de modificación de la Ley de Asociaciones Profesionales (CLAT, diciembre de 1977:5). Además, en la misma Reunión de la OIT el secretario adjunto de la CLAT Luis Henry Molina denunció que el 80\% de los trabajadores y organizaciones de América Latina vivían bajo regímenes de fuerza que violaban los derechos sindicales, laborales y humanos y solicitó al organismo el envío de comisiones investigación a la Argentina, Paraguay, Uruguay, Bolivia y Brasil, similares a la que se "constituyo en 1975 sobre el caso de Chile" y "solicitando que se adopten medidas urgentes para poner fin de la situación dramática de los trabajadores latinoamericanos" (CLAT, diciembre de 1977).

A mediados de 1978 la Central dirigió un cable a la VIII Reunión de la Asamblea General de OEA, que tuvo lugar en Washington, D.C., entre 21 de junio y 1 de julio, 
REVISTA DE LA UNIVERSIDAD DEL ZULIA. 3época. Año 11 N 31, 2020

Mario Ayala/// Solidaridad y denuncia internacional de la CLAT-CMT...271-301

DOI: http://dx.doi.org/10.46925//rdluz.31.18

solicitando al organismo interamericano su intervención urgente en países miembros "a fin de lograr amplia e irrestricta amnistía política libertad inmediata presos políticos sindicales regreso exiliados esclarecimiento desaparecidos particularmente casos Argentina, Chile y Guatemala" (CLAT, julio de 1978: 13).

En 1979 la CLAT planteó el debate en la OIT sobre la situación de América Latina y dejó en evidencia la complicidad de las otras dos centrales sindicales mundiales con la dictadura militar argentina. En esa oportunidad el delegado de Republica Dominicana, perteneciente a la CLAT, denunció la ausencia de libertad sindical en Argentina haciendo notar que su denuncia contrastaba con "el silencio cómplice de la FSM-CPUSTAL y la CIOLS, empeñadas en un extraño, pero no desinteresado, apoyo táctico a las maniobras sindicales del régimen de Videla" (CLAT, julio de 1979: 6).

Durante 1980 la CLAT y la CMT continuaron denunciando a la dictadura argentina ante la OIT por su falta de respeto de los derechos humanos, a las libertades sindicales (CLAT, abril de 1980: 4), atentados contra sindicalistas y la modificación de la Ley de Asociaciones Profesionales (CLAT, enero de 1980: 17). Y para reforzar esta denuncia en la $176^{\circ}$ Sesión del Comité Confederal de CMT exigió al gobierno militar la suspensión de aplicación de la mencionada Ley porque violaba los derechos sindicales consagrados universalmente y era violatoria de las Convenciones de la OIT (CLAT, abril de 1980: 21). Y en mayo, en conferencia de prensa en Santo Domingo, una misión de alto nivel de la CLATCMT destacó su apoyo a "la acción de los trabajadores argentinos contra la nueva Ley de Asociaciones Profesionales, que pretende liquidar todo el poder social económico y político del movimiento obrero organizado para devolver la hegemonía a las oligarquías nacionales y transnacionales" y acordó "llevar a cabo acciones más enérgicas en próxima reunión OIT" respecto al tema (CLAT, junio de 1980: 21). Finamente en la $66^{\circ}$ Conferencia de la OIT de ese año la CLAT denunció varios gobiernos militares latinoamericanos, con énfasis en Argentina y Chile, y exigió respeto de las libertades sindicales y de contratación colectiva y tuvo cruces y disputas con representaciones de ORIT por el apoyo dado por esta central a gobiernos dictatoriales (CLAT, julio de 1980: 20-21).

Como resultado de estas acciones de denuncia y presión de la CLAT y la CMT- y seguramente de otros actores - a fines de 1980 la OIT decidió enviar a la Argentina una 
REVISTA DE LA UNIVERSIDAD DEL ZULIA. 3época. Año 11 N 31, 2020

Mario Ayala/// Solidaridad y denuncia internacional de la CLAT-CMT...271-301

DOI: http://dx.doi.org/10.46925//rdluz.31.18

"Comisión de Juristas" para investigar el cumplimiento del gobierno militar de los "Convenios OIT referentes a la libertad sindical, derecho de huelga y otros derechos sindicales", con el objetivo de hacer un informe al Consejo de Administración de OIT, específicamente al Comité de Libertad Sindical. Esta comisión realizó entrevistas con sindicalistas, familiares de presos y miembros del gobierno y concluyó que "el gobierno argentino violaba sistemáticamente la resolución 87 de OIT sobre libertad sindical" (CLAT, enero de 1981: 4).

En suma, la documentación analizada muestra una actividad sostenida de seguimiento, denuncia y presión de la CLAT y CMT sobre la dictadura militar argentina en la OIT y la OEA hasta por lo menos fines de 1980. Según una declaración emitida por los dirigentes de la CLAT/CMT a inicios de 1981 la organización sindical internacional tenía como orientación principal en la región la búsqueda de "La libertad y la democracia como camino histórico para derrotar definitivamente a las fuerzas totalitarias y genocidas" (CLAT, enero de 1981: 24).

La tercera línea de acción internacional del plan de acción regional que focalizó en Argentina fueron las visitas de misiones sindicales de observación, solidaridad y presión.

4. Misiones sindicales de observación, solidaridad y presión

El envío de misiones de investigación, observación, presión fue un tipo de recurso de acción internacional utilizado por la OIT, Amnistía Internacional y otras organizaciones especializadas en derechos humanos que la CLAT incorporó a sus planes de acción contras las dictaduras por lo menos desde 1976. Al mismo tiempo le agregó el componente político de llevar su solidaridad y apoyo a los reclamos y acciones colectivas de las organizaciones de trabajadores (a veces en general, pero sobre todo a sus afiliadas) en los países bajo dictaduras. Como se mencionó más arriba, las misiones formaban parte de campañas internacionales que incrementaban el impacto en diversos ámbitos.

Las misiones sindicales fueron encabezadas por dirigentes pertenecientes a la CLATCMT y la CTV. La primera misión llegó a Argentina en octubre de 1976 inmediatamente después de la Reunión del Comité Confederado de la CMT en Caracas y de la Declaración sobre los derechos humanos en América Latina (CLAT, diciembre de 1976: 14). Estuvo 
REVISTA DE LA UNIVERSIDAD DEL ZULIA. 3e época. Año 11 N³1, 2020

Mario Ayala/// Solidaridad y denuncia internacional de la CLAT-CMT...271-301

DOI: http://dx.doi.org/10.46925//rdluz.31.18

integrada por una comitiva de dirigentes de la CLAT-CMT y la CTV que también visitaron Chile y Bolivia. Antes de partir de Buenos Aires el Secretario General de la CMT Jan Kulakoski, solicitó en persona a las autoridades militares "la rápida sanción de las siguientes medidas":

1) Libertad inmediata de todos los dirigentes sindicales detenidos sin causas ni proceso; y sustanciación de los cargos que pudiesen existir; 2) Devolución de la CGT a los Sindicatos intervenidos militarmente a legítimos representantes de los trabajadores elegidos libremente; 3 ) respeto de los Convenios Laborales, de las Obras Sociales propiedad de los Sindicatos y de las condiciones de trabajo, desconocidas unilateralmente; 4) Reimplantación de las Convenciones Colectivas de Trabajo, de los principios fundamentales de la Ley de Asociaciones Profesionales y del Derecho de Huelga, disposiciones fundamentales de la legislación Laboral argentina adquiridas por los Trabajadores, cuya violación entraña graves violaciones a los Convenios $\mathrm{N}^{\circ} 87$ y 98 de la OIT. (CLAT, diciembre de 1976: 14)

Esta postura de denuncia y condena de las políticas de las dictaduras in situ indicaba la preocupación de la CLAT-CMT por la situación de la clase trabajadora argentina y sus organizaciones, a las que deseaba acercarse y apoyar en el contexto represivo. Un año después, en septiembre de 1977 una segunda misión al Cono Sur de la CLAT-CMT llegó a la Argentina antes de recorrer Uruguay, Chile y Perú. Su objetivo era solicitar a las dictaduras por los trabajadores presos y desaparecidos, las libertades y derechos de los trabajadores y sus organizaciones, mostrar su preocupación de las políticas económicas que afectaban duramente a la clase trabajadora y "llevar la solidaridad efectiva" a las organizaciones sindicales locales en el marco de su política de "solidaridad de clase en acción". La comitiva fue integrada por Marcel Pepin, Presidente de la CTM, Eduardo García, Secretario general adjunto de la CLAT, Willy Pieriens, Secretario Nacional de la Confederación de Sindicatos Cristianos de Bélgica, Rafael León, Secretario General de la CTV, y Dagoberto González, del Comité Ejecutivo de la CLAT y la CTV. Esta delegación de dirigentes de alto nivel logró entrevistarse con sindicalistas locales, visitar detenidos y entrevistarse con autoridades militares de segunda línea. La dictadura prohibió la publicación y publicidad del comunicado final de la delegación, que fue ampliamente difundido en el exterior (CLAT, octubre de 1977). 
REVISTA DE LA UNIVERSIDAD DEL ZULIA. $3^{a}$ época. Año 11 N 31, 2020

Mario Ayala/// Solidaridad y denuncia internacional de la CLAT-CMT...271-301

DOI: http://dx.doi.org/10.46925//rdluz.31.18

En 1978 otras dos misiones de la CLAT/CMT-CTV visitaron Argentina en los meses de enero ${ }^{10}$ y marzo ${ }^{11}$, reiterando la exigencia de cese de la represión, el respeto a derechos y la libertad de funcionamiento de las organizaciones sindicales y la libertad de presos sindicales y la aparición de desaparecidos, haciendo énfasis en la detención de Roberto Repetto (UPCN, febrero 1978) y las desapariciones de Oscar Smith, Jorge Di Pascuale, entre otros.

Durante 1979 dos nuevas misiones arribaron a la Argentina. La primera fue una delegación de solidaridad de CLAT-CMT-CTV que llego a Buenos Aires en abril para apoyar y estar presente en el primer paro general de la CGT contra dictadura militar convocado para el 28 de ese mismo mes. Fue integrada por una nutrida comitiva de dirigentes encabezada por Ernesto Molano, Secretario General Adjunto de la CMT, Ramón Darío Godoy, parlamentario venezolano y sindicalista perteneciente a la CTV, y Eduardo García Secretario General Adjunto de la CLAT ${ }^{12}$. La presencia de estos dirigentes junto a los trabajadores en lucha en el contexto represivo intentaba expresar -según la CLAT- su posición solidaria con la ola huelgas obreras en la región - Nicaragua, Brasil, Perú - y su expectativa en que la movilización de masas obreras contra las dictaduras fueron reconocidas como un método para el derrocamiento y apertura política hacia la democracia (CLAT, mayo de 1979). Inmediatamente después del paro la misión CLAT-CMT gestionó la libertad de sindicalistas presos durante la medida de fuerza y formuló una enérgica protesta al gobierno militar. Su balance del paro fue publicado en el Informativo CLAT y destacaba que el "movimiento obrero organizado" era "el factor de oposición más eficaz contra las dictaduras y el agente más decisivo para el desarrollo y consolidación de las nuevas democracias"; denunciando el apoyo de CIOLS-ORIT-AFL-CIO a la dictadura argentina, mostrando una actitud "colaboracionista" con su negativa a apoyar el paro general (CLAT, mayo de 1979:8-17).

${ }^{10}$ La Misión visitó Argentina y Paraguay y fue encabezada por los dirigentes sindicales venezolanos Rafael León León, parlamentario y Secretario General de la CTV, quien fue acompañado por el Secretario General de FEDEPETROL-CLAT.

"l Misión de la CLAT a la Argentina precedida por Andrés Mercau, diputado venezolano y Secretario General de FETRAMETAL-CLAT.

${ }^{12} \mathrm{El}$ paro general había sido convocado para el 28 de abril un grupo de sindicalistas de la CGT intervenida conocido como la "Comisión de los 25" a los que la CLAT consideraba "el sector más representativito y mayoritario del movimiento obrero argentino". 
REVISTA DE LA UNIVERSIDAD DEL ZULIA. 3época. Año 11 N 31, 2020

Mario Ayala/// Solidaridad y denuncia internacional de la CLAT-CMT...271-301

DOI: http://dx.doi.org/10.46925//rdluz.31.18

La segunda misión de 1979 visitó Argentina en mayo, a un mes del paro general con la intención de "expresar sobre el terreno la solidaridad de clase con el movimiento obrero de esos países y solicitar la libertad de los dirigentes sindicales presos, el cese de la represión, el levantamiento de todas restricciones que pesan sobre el Movimiento Obrero organizado" (CLAT, junio de 1979:19). La misión también visitó Perú y Chile y estuvo formada por los sindicalistas venezolanos Rafael León León, Secretario General de la CTV, Ramón Petit dirigente petrolero de CTV, Luis Guevara Manosalva, dirigente del Colegio Nacional Periodistas de Venezuela y de la FELATRAP.

Las misiones de observación, presión y solidaridad enviadas por la CLAT/CMT a la Argentina en 1979 fueron las últimas que se propusieron denunciar las violaciones de derechos humanos y sindicales. Hubo una última en abril de 1982 pero fue para solidarizarse con la guerra de Malvinas, como mencionamos en el segundo apartado.

A modo de balance general puede afirmarse que para el caso de la Argentina durante la última dictadura militar, sobre todo entre 1976 y 1979, se observó que la CLAT-CTM realizó campañas que incluyeron la denuncia en la esfera pública internacional, en organismos internacionales y el envío misiones de misiones de observación, presión y solidaridad. Este trabajo se realizó dentro de sus planes de acción regionales hacia las aéreas más afectadas por las dictaduras de Seguridad Nacional en el Cono Sur, incluyendo a Perú, Bolivia y Paraguay. Sus documentos indican que tuvieron mayor impacto en países como Perú que en Argentina, Brasil o Chile. Aunque el efecto denuncia internacional fue importante y la solidaridad efectiva significativa para las organizaciones que llevaban adelante las luchas. Las misiones también ayudaron a visualizar la propuesta de la CLATCTM en la región e impulsar su estrategia de formación política y articulación sindical regional a partir de asociaciones de sindicatos y centrales nacionales.

Una pregunta que queda abierta para futuras investigaciones. ¿Por qué la información de acciones de denuncia de las violaciones de los derechos humanos y sindicales de la CLAT en relación a Cono Sur se reduce a partir de 1980? El análisis de su prensa indica una de las razones hay que buscarlas en el escenario de luchas insurreccionales, guerras civiles, conflictos laborales y represión en Centroamérica después del triunfo de la revolución en Nicaragua; y en la apertura democrática en República 
REVISTA DE LA UNIVERSIDAD DEL ZULIA. 3e época. Año 11 N³1, 2020

Mario Ayala/// Solidaridad y denuncia internacional de la CLAT-CMT...271-301

DOI: http://dx.doi.org/10.46925//rdluz.31.18

Dominicana y Perú. Todos lugares donde la CLAT/CMT tenía bases sindicales significativas y en expansión. Pero el evento que cambio las prioridades de la agenda parece haber sido la crisis centroamericana, a donde se dirigió el interés de la opinión pública y de los actores políticos y sindicales regionales e internacionales, incluido el de la CLA/CMT.

\section{Consideraciones finales}

La conclusión general de este artículo es que el trabajo solidaridad y denuncia internacional de la CLAT-CMT hacia las violaciones de los derechos humanos y sindicales en Argentina se planificó dentro de sus planes de acción en el Cono Sur bajo dictaduras de Seguridad Nacional, con el apoyo sus organizaciones aliadas en Venezuela y la región; y se ejecutó mediante tres tipos de acciones que se articularon de diversa forma según la coyuntura y las prioridades: 1) campañas internacionales de información y denuncia ante gobiernos extranjeros y la opinión pública mundial; 2) denuncia en organismos internacionales; 3) envío al país de misiones de observación, solidaridad y presión.

Este primer avance de investigación permite además presentar una serie de hallazgos e hipótesis que deberán ser profundizados en futuras investigaciones.

En primer lugar, el estudio de las posiciones y acciones de la CLAT/CMT expresadas en su prensa periódica, documentos, declaraciones públicas permiten afirmar que Venezuela, en tanto sede de esta organización sindical internacional, fue un país desde donde se realizaron acciones denuncia contra las violaciones de los derechos humanos y sindicales y la política laboral de la dictadura argentina. La reconstrucción realizada mostró la dimensión transnacional de los planes de acción de la CLAT/CMT en el marco global de la Guerra Fría y en sus escalas regionales y nacionales, a partir del rol de la CODESA y la CTV en acciones que se activaron desde Venezuela hacia la región y el mundo, así a como las agrupaciones sindicales afiliadas a la CLAT dentro de Argentina nucleadas en el Consejo Coordinador Sindical Argentino (CCAS).

En segundo lugar, se comprobó que la CLAT-CMT reclamó desde el inicio de la última dictadura militar argentina por los derechos de los trabajadores, denunció la intervención de los sindicatos y la política represiva de asesinatos, desapariciones y encarcelamientos de obreros y sindicalistas ante organismos internacionales, gobiernos 
REVISTA DE LA UNIVERSIDAD DEL ZULIA. 3época. Año 11 N 31, 2020

Mario Ayala/// Solidaridad y denuncia internacional de la CLAT-CMT...271-301

DOI: http://dx.doi.org/10.46925//rdluz.31.18

extranjeros y la opinión pública internacional; y envío a la Argentina anualmente misiones de observación y solidaridad, principalmente entre 1976 y 1979.

En tercer lugar, se pudo demostrar que su estrategia de trabajo de solidaridad y denuncia internacional se inscribió en la tradición de solidaridad internacional del movimiento obrero occidental, pero en el contexto de la Guerra Fría global (e interamericana) esta se orientó hacia actores de identidad socialcristiana. La CLAT/CMT incorporó las modalidades de trabajo de las modernas redes transnacionales de defensa de los derechos humanos - estudiadas por Keck y Sikkink (1999) - que se potenciaron desde principios de la década del setenta y lograron influir en la política internacional en relación a las violaciones de los derechos humanos en la región.

En cuarto lugar, desde una perspectiva general, se evidenció que desde mediados de los setenta la denuncia de la represión dictatorial y la defensa de los derechos humanos, junto con las "acciones de solidaridad de clase activas", se transformaron en uno de los ejes de acción fundamentales de la CLAT/CMT hasta la década de 1980. Esta actividad de denuncia y solidaridad sindical humanitaria fue el resultado de su experiencia de trabajo organizativo y de defensa de los derechos sindicales de los trabajadores latinoamericanos en las condiciones concretas de las luchas y el desarrollo organizativo del movimiento obrero de las décadas de 1960 y 1970. Además, tampoco debe omitirse que esta actividad contribuyó (calculadamente o no) a la visualización y crecimiento del proyecto de la CLAT en la región y también a la acumulación de capital político como actor sindical internacional en sus disputas con las ORIT y la CPUSTAL.

En quinto lugar, estas definiciones de la CLAT y su carácter de organización sindical internacional hicieron a que sus acciones de denuncia y solidaridad se concentraran casi exclusivamente en el ámbito sindical y en casos de militantes y profesionales vinculados al mundo sindical y socialcristiano argentino. Recién hacia mediados de 1979 se observa una ampliación de su línea de denuncia y solidaridad, a partir de su apoyo a la lucha de los organismos de derechos humanos argentinos y las organizaciones de solidaridad y apoyo con los exiliados. A pesar de esto, todas sus fuerzas y recursos continuaron siendo destinados a la denuncia y solidaridad con los sindicatos y sus activistas. 
REVISTA DE LA UNIVERSIDAD DEL ZULIA. 3época. Año 11 N 31, 2020

Mario Ayala/// Solidaridad y denuncia internacional de la CLAT-CMT...271-301

DOI: http://dx.doi.org/10.46925//rdluz.31.18

Referencias

Affatatto, C. (2013) Exilio argentino en Venezuela [Entrevista In person]. Ramos Mejía, Argentina.

Antentas, J. M. \& Vivas, E. (2009). Internacionalismo(s): ayer y hoy. Viento Sur, No.100, 3340.

Ayala, M. (2017). Exiliados argentinos en Venezuela (1974-1983). (Tesis de doctorado) Facultad de Filosofía y Letras de la Universidad de Buenos Aires. Buenos Aires.

Canelo, P. (2004). La política contra la economía: los elencos militares frente al plan económico de Martínez de Hoz durante el Proceso de Reorganización Nacional (19761981). Pucciarelli, A. (comp.). Empresarios, tecnócratas y militares. La trama corporativa de la última dictadura. Buenos Aires: Siglo XXI, 218-312

CLAT (1976). 168 Reunión del Comité Confederal CMT. Frente a los sistemas totalitarios, es preciso desarrollar la solidaridad internacional de clase. Informativo CLAT. Vocero del movimiento de los trabajadores comprometidos con la liberación de los pueblos de América Latina (Caracas) Año 1, N 8, Noviembre, pp. 8 y 9.

CLAT (1976). CLAT presiona para libertad de presos sindicales en Argentina. Informativo CLAT. Vocero del movimiento de los trabajadores comprometidos con la liberación de los pueblos de América Latina (Caracas) Año 1, N 6, Diciembre, p. 4.

CLAT (1976). Declaración de la CMT sobre situación de Derechos Humanos en América Latina. Informativo CLAT. Vocero del movimiento de los trabajadores comprometidos con la liberación de los pueblos de América Latina, (Caracas) Año 1, N 6, Diciembre, p. 5.

CLAT (1976). La CLAT y los Derechos Humanos. Cuadernos de la CLAT, Año 1, Nºl, Septiembre-Noviembre, p. 69.

CLAT (1976). Visita del Secretario General de la CTM a la Argentina. Informativo CLAT. Vocero del movimiento de los trabajadores comprometidos con la liberación de los pueblos de América Latina (Caracas), Año 1, N 9, Diciembre, p. 14.

CLAT (1977) Reclaman por la libertad de Daniel Esquivel. Informativo CLAT. Vocero del movimiento de los trabajadores comprometidos con la liberación de los pueblos de América Latina (Caracas), Año 2, N 15, Diciembre.

CLAT (1977). Amnistía General de Presos Sindicales y Políticos. Informativo CLAT. Vocero del movimiento de los trabajadores comprometidos con la liberación de los pueblos de América Latina (Caracas), Año 2, N 15, Diciembre, p. 1. 
REVISTA DE LA UNIVERSIDAD DEL ZULIA. $3^{a}$ época. Año $11 N^{\circ}$ 31, 2020

Mario Ayala/// Solidaridad y denuncia internacional de la CLAT-CMT...271-301

DOI: http://dx.doi.org/10.46925//rdluz.31.18

CLAT (1977). Argentina. Grave situación a un año del golpe. Informativo CLAT. Vocero del movimiento de los trabajadores comprometidos con la liberación de los pueblos de América Latina (Caracas) Año 2, Abril, N 12, p. 16.

CLAT (1977). Argentina. Para ganar un paz justa y efectiva. Informativo CLAT. Vocero del movimiento de los trabajadores comprometidos con la liberación de los pueblos de América Latina (Caracas) Año 2, N¹9, Noviembre, p. 6.

CLAT (1977). Argentina: se agudiza el enfrentamiento de los sindicatos con el gobierno. Informativo CLAT. Vocero del movimiento de los trabajadores comprometidos con la liberación de los pueblos de América Latina (Caracas), Año 2, N¹5, Diciembre, p. 5.

CLAT (1977). Campaña para garantizar la vida de Jorge Di Pascuale. Informativo CLAT. Vocero del movimiento de los trabajadores comprometidos con la liberación de los pueblos de América Latina (Caracas) Año 2, N 9, Febrero, p. 11.

CLAT (1977). Informativo CLAT. Vocero del movimiento de los trabajadores comprometidos con la liberación de los pueblos de América Latina (Caracas) Año 2, N²0, Diciembre, p. 13.

CLAT (1977). Libertad a Alfredo Carazo. Informativo CLAT. Vocero del movimiento de los trabajadores comprometidos con la liberación de los pueblos de América Latina (Caracas) Año 2, N¹3, Mayo, p. 1.

CLAT (1977). Misión CLAT-CMT a países del Cono Sur. Informativo CLAT. Vocero del movimiento de los trabajadores comprometidos con la liberación de los pueblos de América Latina (Caracas), Año 2, N 18, Octubre.

CLAT (1977). Solicitan el envío de Comisiones de Investigadoras a paises del Cono Sur. Informativo CLAT. Vocero del movimiento de los trabajadores comprometidos con la liberación de los pueblos de América Latina. (Caracas) Año 2, N¹5, Diciembre.

CLAT (1977). Venezuela: reacciones ante la visita de Videla. Informativo CLAT. Vocero del movimiento de los trabajadores comprometidos con la liberación de los pueblos de América Latina (Caracas) Año 2, N¹4, Junio, p. 8.

CLAT (1978) Sólo el poder detiene al poder. Acuerdos del VII Congreso sobre programa de reivindicaciones, de organización y acción, sobre acción profesional y sobre política de organización de cuadros y formación global. Caracas: FLACPO.

CLAT (1978). Agudizada lucha de bloques imperialistas. IX Congreso Federación Sindical Mundial: más que nunca bajo el imperio soviético. Informativo CLAT. Vocero del movimiento de los trabajadores comprometidos con la liberación de los pueblos de América Latina (Caracas) Año 3, $\mathrm{N}^{\circ}$ 25, Junio, p. 16-17; en: International Institute of Social History, Amsterdam, Holanda (en adelante IISH). 
REVISTA DE LA UNIVERSIDAD DEL ZULIA. $3^{a}$ época. Año 11 N 31, 2020

Mario Ayala/// Solidaridad y denuncia internacional de la CLAT-CMT...271-301

DOI: http://dx.doi.org/10.46925//rdluz.31.18

CLAT (1978). Amílcar González recobra la libertad. Un nuevo triunfo de la solidaridad de clase. Terminan dos largos años de arbitraria detención. Informativo CLAT. Vocero del movimiento de los trabajadores comprometidos con la liberación de los pueblos de América Latina (Caracas) Año 3, N²4, Caracas, Junio, p. 13.

CLAT (1978). Amílcar González. Dos años de su detención. La FELATRAP reitera su pedido de inmediata libertad. Informativo CLAT. Vocero del movimiento de los trabajadores comprometidos con la liberación de los pueblos de América Latina (Caracas) Año 3, N²2, Marzo, p. 7.

CLAT (1978). CLAT refuerza su solidaridad de clase. Informativo CLAT. Vocero del movimiento de los trabajadores comprometidos con la liberación de los pueblos de América Latina (Caracas) Año 3, $\mathrm{N}^{\circ} 28$, Septiembre.

CLAT (1978). La CLAT denuncia desaparición de un dirigente gremial argentino. Informativo CLAT. Vocero del movimiento de los trabajadores comprometidos con la liberación de los pueblos de América Latina (Caracas) Año 3, N²4, Junio, p. 5.

CLAT (1978). Mensaje a la VIII Asamblea de la OEA. Informativo CLAT. Vocero del movimiento de los trabajadores comprometidos con la liberación de los pueblos de América Latina (Caracas), $\mathrm{N}^{\circ}$ 26, Julio 1978, p. 13.

CLAT (1979). Argentina: Amplio apoyo de la clase trabajadora al primer paro general contra el régimen militar. Informativo CLAT. Vocero del movimiento de los trabajadores comprometidos con la liberación de los pueblos de América Latina (Caracas), Año 4, N³5, Mayo, pp. 8-17.

CLAT (1979). Argentina: Enérgica protesta ante represión contra organizaciones proDerechos Humanos. Informativo CLAT. Vocero del movimiento de los trabajadores comprometidos con la liberación de los pueblos de América Latina (Caracas) Año 4, N³8, Agosto, p. 8

CLAT (1979). Jornadas de Solidaridad Latinoamericana. Informativo CLAT. Vocero del movimiento de los trabajadores comprometidos con la liberación de los pueblos de América Latina (Caracas) Año 4, $N^{\circ} 34$, Abril.

CLAT (1979). La clase trabajadora pasa a la ofensiva. Informativo CLAT. Vocero del movimiento de los trabajadores comprometidos con la liberación de los pueblos de América Latina (Caracas), Año 4, $\mathrm{N}^{\circ}$ 35, Mayo.

CLAT (1979). La derrota del Fascismo. Dos décadas de lucha de la clase trabajadora latinoamericana. Informativo CLAT, Año 4, $\mathrm{N}^{\circ}$ 4l, Noviembre-Diciembre.

CLAT (1979). Libertad sindical en Argentina. Informativo CLAT. Vocero del movimiento de los trabajadores comprometidos con la liberación de los pueblos de América Latina (Caracas), Año 4, N³7, Julio, p. 6. 
REVISTA DE LA UNIVERSIDAD DEL ZULIA. $3^{a}$ época. Año 11 N 31, 2020

Mario Ayala/// Solidaridad y denuncia internacional de la CLAT-CMT...271-301

DOI: http://dx.doi.org/10.46925//rdluz.31.18

CLAT (1979). Misión especial de CLAT-CMT lleva solidaridad activa y concreta a la clase trabajadora el pueblo de Argentina, Chile y Perú. Informativo CLAT. Vocero del movimiento de los trabajadores comprometidos con la liberación de los pueblos de América Latina (Caracas), Año 4, N 36, Junio, p. 19.

CLAT (1979). Sindicatos argentinos formulan pedido un intervención al presidente de Venezuela. Informativo CLAT. Vocero del movimiento de los trabajadores comprometidos con la liberación de los pueblos de América Latina (Caracas) Año 4, N³3, Marzo, p. 3

CLAT (1979).Organizaciones europeas demandan libertad de sindicalistas argentinos. Informativo CLAT. Vocero del movimiento de los trabajadores comprometidos con la liberación de los pueblos de América Latina (Caracas) Año 4, N³4, Abril, p. 22

CLAT (1980). Firme oposición ante nueva Ley de Asociaciones Profesionales. Informativo CLAT. Vocero del movimiento de los trabajadores comprometidos con la liberación de los pueblos de América Latina (Caracas), Año 5, N 42, Enero, p. 17.

CLAT (1980). Impulsar la participación de los trabajadores en la dirección y control de las empresas. Informativo CLAT. Vocero del movimiento de los trabajadores comprometidos con la liberación de los pueblos de América Latina (Caracas) Año 5, Nº 5l, Octubre, p. 5;

CLAT (1980). La CLAT ante la 66 Conferencia de la OIT'. Informativo CLAT. Vocero del movimiento de los trabajadores comprometidos con la liberación de los pueblos de América Latina (Caracas), Año 5, N 48, Julio, pp. 20-21.

CLAT (1980). Los Derechos Humanos y la libertad sindical siguen siendo reprimidos en América Latina. Misión de la CLAT-CMT formuló declaraciones en Santo Domingo. Informativo CLAT. Vocero del movimiento de los trabajadores comprometidos con la liberación de los pueblos de América Latina (Caracas), Año 5, N 47, Junio, p.21.

CLAT (1980). Plan de Acción de los Trabajadores Latinoamericanos. Informativo CLAT. Vocero del movimiento de los trabajadores comprometidos con la liberación de los pueblos de América Latina (Caracas) Año 5, N 43, Febrero, pp. 23-24

CLAT (1980). Repudian atentado contra dirigente sindical argentino. Informativo CLAT. Vocero del movimiento de los trabajadores comprometidos con la liberación de los pueblos de América Latina (Caracas), Año 5, N 45, Abril, p. 4.

CLAT (1980). Solidaridad con los trabajadores argentinos. Informativo CLAT. Vocero del movimiento de los trabajadores comprometidos con la liberación de los pueblos de América Latina (Caracas), Año 5, N 45, Abril, p.21.

CLAT (1981). Argentina: La CLAT denuncia represión contra el SERPAJ y el premio Nobel de la Paz Adolfo Pérez Esquivel. Informativo CLAT. Vocero del movimiento de los trabajadores comprometidos con la liberación de los pueblos de América Latina (Caracas) Año 6, N 59, Julio, p. 9. 
REVISTA DE LA UNIVERSIDAD DEL ZULIA. $3^{a}$ época. Año 11 N 31, 2020

Mario Ayala/// Solidaridad y denuncia internacional de la CLAT-CMT...271-301

DOI: http://dx.doi.org/10.46925//rdluz.31.18

CLAT (1981). La libertad y la democracia como camino histórico para derrotar definitivamente a las fuerzas totalitarias y genocidas. Informativo CLAT. Vocero del movimiento de los trabajadores comprometidos con la liberación de los pueblos de América Latina (Caracas), Año 6, $\mathrm{N}^{\circ}$ 53, Diciembre1980-Enero 1981, p.24.

CLAT (1981). Libertad sindical en la Argentina reclama Comisión de Juristas OIT. Informativo CLAT. Vocero del movimiento de los trabajadores comprometidos con la liberación de los pueblos de América Latina (Caracas), Año 6, N 53, Diciembre1980-Enero 1981, p.4.

CLAT (1982). El Conflicto de Malvinas. Reunión del Comité Ejecutivo de la CMT con dirigentes de la CGT de Argentina. Informativo CLAT. Vocero del movimiento de los trabajadores comprometidos con la liberación de los pueblos de América Latina (Caracas) Año 7, N 64, Junio, p. 2

CLAT. (1980). No a la subversión aventurera si a la democratización real. Informativo CLAT. Vocero del movimiento de los trabajadores comprometidos con la liberación de los pueblos de América Latina (Caracas) Año 5, N 44, Marzo de 1980, p.2

CMT (1976). "Declaración contra el fascismo en América latina del Comité Confederal de la CMT". Cuadernos de la CLAT (Caracas) Año 1, № 1, Septiembre-Noviembre, pp. 93-97.

Dirección de Inteligencia de la Policía de la Provincia de Buenos Aires (DIPBA) (1982). Información relacionada con misión solidaridad de los trabajadores venezolanos (Quilmes, Buenos Aires) 7 de Junio; en: Archivo de la DIPBA, Comisión Provincial de la Memoria (ADIPBA-CPM), La Plata, Buenos Aires, Argentina.

Franco, M. (2008). El Exilio: argentinos en Francia durante la dictadura. Buenos Aires: Siglo XXI Editores.

Franco, M. (2012). Un enemigo para la nación. Orden, violencia y "subversión", 1973-1976. Buenos Aires: Fondo de Cultura Económica.

Gilman, C. (2003). Entre la pluma y el fusil: debates y dilemas del escritor revolucionario en América Latina. Buenos Aires: Siglo Veintiuno Argentina.

Godio, J. \& Wachendorfer, A. (1986). Las internacionales sindicales. Nueva Sociedad (Caracas) $\mathrm{N}^{\circ}$ 83, Mayo-Junio.

Gordillo, M. (2020). Formación sindical en la Argentina postdictadura: pluralismo ideológico, unidad e integración latinoamericana. Sociohistórica, (45).

Gordillo, Mónica (2017). Activismo sindical transnacional en el Cono Sur: algunas experiencias. Clepsidra. Revista Interdisciplinaria de Estudios sobre Memoria (Buenos Aires), № 7.

Harmer, T. (2013). El gobierno de Allende y la Guerra Fría Interamericana. Santiago de Chile: Ediciones Universidad Diego Portales. 
REVISTA DE LA UNIVERSIDAD DEL ZULIA. 3época. Año 11 N 31, 2020

Mario Ayala/// Solidaridad y denuncia internacional de la CLAT-CMT...271-301

DOI: http://dx.doi.org/10.46925//rdluz.31.18

Jensen, S. (2010). Los exiliados. La lucha por los derechos humanos durante la dictadura. Buenos Aires: Sudamericana.

Keck, M. y Sikkink, K. (1999). Las redes transnacionales de defensa en la política internacional y regionales. International Social Sciencie Journal, No. 159.

Panella, C. (2017). La Nación y la ley de Asociaciones Profesionales de 1973: un poder «casi ilimitado» a los dirigentes sindicales. Actas de Periodismo y Comunicación, Vol. 3, № 3, diciembre.

Parcero, D. \& Morant, M. (2016). El sindicalismo argentino: de no alineado a la unidad global. Buenos Aires: CICCUS.

Parcero, D. (1987). La CGT yel sindicalismo latinoamericano. Buenos Aires: Editorial Fraterna.

Parker, D. (1988). El sindicalismo cristiano latinoamericano en busca de un perfil propio: 1954-1971. Caracas: Consejo de Desarrollo Científico y Humanístico, Universidad Central de Venezuela.

Pettinà, V. (2018). Historia mínima de la guerra fría en América Latina. México: El Colegio de México.

Scodeller, G. (2011). La formación político-sindical de los trabajadores socialcristianos en la Argentina de los años '60. Anuario del Centro de Estudios Históricos "Prof. Carlos S. A. Segreti" (Córdoba), año ll, No. 11.

Scodeller, G. (2015). De una "conciencia mágica e ingenua" a otra "crítica y política": la formación en la Central Latinoamericana de Trabajadores (CLAT) durante los '60 y '70. Ponencia en IV Congreso Internacional de Ciencias, Tecnologías y Culturas, 9-12 de octubre 2015, Universidad de Santiago de Chile.

Scodeller, G. (2016). Political Training and Social Change in the 1960s and 1970s: The Educational Activities of the Latin American Central of Workers (CLAT). International Labor and Working-Class History, No. 90.

Slatman, M.; Serra Padros, E. (2014). Brasil y Argentina: modelos represivos y redes de coordinación durante el último ciclo de dictaduras del Cono Sur. Estudio en clave comparativa y transnacional. En: Jensen, S. y Lastra, S. (edits.). Exilios: militancia y represión. Nuevas fuentes, nuevos abordajes de los destierros de la Argentina en los años setenta. La Plata, Argentina: EDULP.

Suriano, J. dir. (2003). Dictadura y democracia (1976-2001). Nueva Historia Argentina, tomo X. Buenos Aires: Sudamericana.

Thesing, J. (2011). La fundación Konrad Adenauer en América Latina: historia de una larga cooperación. Segunda parte. Diálogo Político. vol. 28, no. 1. 
REVISTA DE LA UNIVERSIDAD DEL ZULIA. 3르 época. Año 11 Nº 31, 2020 Mario Ayala/// Solidaridad y denuncia internacional de la CLAT-CMT...271-301 DOI: http://dx.doi.org/10.46925//rdluz.31.18

Wahlers, G. (1991). Nace una alternativa: CLAT: historia de una internacional sindical latinoamericana. Miami: Saeta.

Yankelevich, P. (2010). Ráfagas de un exilio. Argentinos en México (1974-1983). Buenos Aires: Fondo de Cultura Económica-El Colegio de México. 